To the Editors:

\title{
Causes of headache in a Sri Lankan general practice
}

Headache is a common experience of otherwise healthy adults in a community often causing heavy use of investigations and inappropriate therapy $(1,2)$. Yet studies reporting on causes of headache in primary care are few (3,4). I conducted a study to find out the causes of headache in my practice.

All patients who consulted with headache as the main clinical problem were included in the study. Each patient's headache was diagnosed using a data collection form during the course of routine consultation. The data collection form was a computer program [Headache Assessment Questionnaire (HAQ)] developed by me for use in my practice. HAQ consists of 47 questions each of which has a yes or no answer. The questions were designed to generate International Headache Society (IHS) (5) or International Association for Study of Pain (6) criteria based diagnoses. When such standardised criteria could not be collected, standard textbook descriptions were used to design the questions. HAQ can diagnose 21 common causes of headache in primary care.

The study sample comprised 222 patients. $47.3 \%$ had tension type headache and $27 \%$ had migraine. $14 \%$ could not be diagnosed. $9.5 \%$ had post-traumatic headache. $13.5 \%$ and $4 \%$ had acute sinusitis and eye disease respectively. The majority (71\%) had only one type of headache, but $28 \%$ had "mixed" headaches. The commonest combination was migraine and tension type headache. $32 \mathrm{pa}$ tients (14.4\%) could not be diagnosed using the current HAQ. Of them 6 had ultra-short attacks (headache attack duration $<1 / 2 \mathrm{~h}$ ) which could be diagnosed using the available IHS criteria: cluster headache 1 , SUNCT syndrome 1, Jabs and Jolt syndrome 2, cough headache 1, TIA 1. 20 patients had a similar group of markings in the
HAQ and 6 patients did not have any obvious common features among them. The group of 20 patients with similar markings had the following features: headache duration less than 2 weeks, mild severity, first ever episode, not febrile, no evidence of hypertension, no ENT or dental problems.

Using standardised and acceptable criteria more than $85.6 \%$ of patients presenting with headache to a general practitioner can be diagnosed. These data should help primary care physicians to employ an evidence based approach (pretest probability and likehood ratios of individual signs and symptoms) to diagnose the cause(s) of headache.

\section{References}

1. Kroenke K, Price R. Symptoms in the community: a population based study. Clinical Research 1991; 39: 579A.

2. Kroenke K. Symptoms in medical patients: an untended field. The American Joumal of Medicine 1992; 92: 1A-3S.

3. Stang PE, Von Korff M. The diagnosis of headache in primary care: factors in the agreement of clinical and standardized diagnosis. Headache 1994; 34: 138-42.

4. Bigal ME, Bordini CE, Speciali JG. Etiology and distribution of headaches in two Brazilian primary care units. Headache 2000; 40: 241-7.

5. Headache Classification Committee of the International Headache Society. Classification and diagnostic criteria for headache disorders, cranial neuralgias and facial pain. Cephalalgia 1988; 8: 196.

6. Classification of Chronic Pain: Description of chronic pain syndromes and difinitions of pain terms. 2nd Edition. International Association for the Study of Pain. Seattle: IASP Press, 1999.

Ananda Perera, Family Physician, Medical Centre, St. Joseph's Street, Negombo. 